\title{
Paroxysmal myoclonic dystonia with vocalisations: new entity or variant of preexisting syndromes?
}

\author{
TODD E FEINBERG, ${ }^{*}$ ARTHUR K SHAPIRO,$\dagger$ ELAINE SHAPIRO,$\dagger$ \\ From the Departments of Neurology, ${ }^{*}$ and Psychiatry and Tourette and Tic Laboratory and Clinic, $\dagger$ Mount \\ Sinai School of Medicine, New York, USA
}

SUMMARY From among 1377 patients with movement disorders, four patients had an unusual movement disorder characterised by paroxysmal bursts of involuntary, regular, repetitive, rhythmic, bilateral, coordinated, simultaneous, stereotypic myoclonus and vocalisations, often associated with tonic symptoms, interference with voluntary functioning, presence of hyperactivity, attention and learning disabilities, and resistance to treatment with haloperidol and other drugs. This symptom complex may represent a new disease entity, referred to here as paroxysmal myoclonic dystonia with vocalisations or a variant or combination of other movement disorders such as Gilles de la Tourette, myoclonic, or dystonic syndromes.

Between 1965 and 1983 we have examined 1377 patients thought to have a -tic disorder. Although most (82\%) were diagnosed as having Gilles de la Tourette syndrome,,$^{23} 31(2 \cdot 3 \%)$ patients were diagnosed as having an atypical movement disorder because they did not fulfill DSM $\mathrm{II}^{2}$ or other ${ }^{34}$ criteria for Gilles de la Tourette syndrome or any other known movement disorder. We recently reviewed the history, signs, symptoms and clinical course to ascertain whether there were common factors or similarities among these patients. Several patterns emerged suggesting new movement entities or atypical forms of other movement disorders. This paper focuses on one such entity referred to by us as paroxysmal myoclonic dystonia with vocalisations.

These patients had a movement disorder characterised by paroxysmal bursts of involuntary, regular, repetitive, rhythmic, bilateral, stereotypic and severe myoclonus with vocalisations often associated with tonic movements, and which interfered with-voluntary behaviour. These patients also had mild attention deficit disorder, hyperactivity, learning disabilities, and resistance to treatment with haloperidol. This paper describes the signs, symptoms and clinical course for these patients and dis-

Address for reprint requests: Arthur K Shapiro, MD, Mount Sinai School of Medicine Tourette and Tic Laboratory and Clinic, Annenberg Building, Room 22-72, One Gustave L Levy Place, New York, New York 10029, USA.

Received 27 April 1984 and in revised form 29 January 1985. Accepted 23 March 1985 cusses the differential diagnosis. The possibility of a new diagnostic entity is considered as well as the possibility that the symptoms represent a spectrum varying between or the coexistence of Gilles de la Tourette, myoclonic, and dystonic disorders.

\section{Methods}

Each patient had a comprehensive two-hour diagnostic evaluation which included completion by the patient anc review by AKS of a detailed Movement Disorder Questionnaire and previous medical and psychiatric records, interview of the patient, spouse or parents, and screening physical and neurological examination. The data derived from the Movement Disorder Questionnaire comprise demographic, family movement disorder and medical histories, birth, developmental, and patient past and current medical histories, psychological, social, academic and occupational functioning, and symptom and treatment histories.

Patients diagnosed as Atypical Movement Disorder did not fulfill criteria for any movement disorder known to us, such as Gilles de la Tourette syndrome; simple, chronic or multiple motor tics; transient tic of childhood; focal, segmental of generalised torsion dystonia; stereotypic movement disorder; Huntington's chorea; tardive dyskinesia; myoclonic epilepsy; cough of adolescence or adulthood; myoclonus; essential tremor; etc. The diagnosis required agreement by the three authors. The records of these patients were reviewed repetitively, and selected patients were reinterviewed. In addition to reconstructing from the patients history and records the onset, progression and nature of the abnormal movements, we had the opportunity in two cases to videotape examples of the movements. We include here the results of the videotape analysis, in 
addition to historical accounts, because we feel the exactness of such an analysis supplements and at times exceeds what the patients are aware of or observers can record with the unaided eye.

\section{Case descripṭons}

Case 1 is a 21 -year-old white male. Family medical and movement disorder histories, perinatal period and developmental milestones are non-contributory. The first symptom of a movement disorder began at age 8 years with a loud inspiratory and expiratory throat clearing that was longer in duration than a typical tic. A repetitive, rough, guttural, inspiratory coughing sound occurred at age 10, followed at 14 by a repetitive tonic back-bending or opisthotonic movement, insertion of finger in the throat and external throat touching. At age 18 he developed a tonic flexing of the arms at the elbow.with superimposed repetitive myoclonic jerks, and a year later developed a tonic movement of the neck to the right and horizontally with superimposed repetitive myoclonic movements. Repetitive sounds included throat clearing, coughs, grunts, barks, screams, and high-pitched spitting sounds. Occasional coprolalia was described as involuntary but was characterised by the repetitive and regular utterance of the same word more slowly than is usual in Gilles de la Tourette syndrome. The symptomatology has a waxing, waning and fluctuating clinical course. Symptoms partially decrease in the presence of strangers and with non-anxious absorption in a task in the manner of Gilles de la Tourette syndrome. But the movements, unlike those in Gilles de la Tourette syndrome, were the same in school as in the presence of the family, could not be voluntarily stopped, and would interrupt non-anxious absorption in tasks such as building models, when objects would be dropped owing to the spasms. The patient had unsuccessful therapeutic trials with haloperidol and other neuroleptics, reserpine, benzodiazepines, sedative-hypnotics, antiseizure medications, clonidine, clonazepam, psychotherapy, behavioural therapy, and relaxation therapy. The general physical examination was unremarkable except for a fine distal tremor bilaterally on finger to nose test, slightly clumsy fine finger and rapid alternating movements, and one or two beats of clonus at the ankles bilaterally. The patient had a normal EEG, CT scan and lumbar CSF. Copper studies were negative. Psychological tests done at age 18 revealed a low average IQ of 88 without VIQ-PIQ discrepancy, normal Bender-Gestalt and MMPI, slight depression of short-memory and academic skills, evidence of attention deficit disorder, hyperactivity, and serious learning disabilities. There was no evidence of psychosis, although the patient was dependent and immature.

Videotape analysis. The initial two-hour interview was recorded on videotape. The videotape was intensively reviewed by TF and AKS. Real time, frame by frame, and freeze-action analysis enabled precise measurement of the movement characteristics. Proximal and distal muscle groups were involved in all movements, with proximal groups demonstrating more tonic and distal groups more myoclonic movements. Movements were predominantly in muscles of the neck, dorsal trunk, shoulders and arms. Few movements were noted in the legs. Myoclonic movements typically involved a muscle group and its synergists, while tonic movements simultaneously involved agonists and antagonists. Movements were bilateral and of large amplitude, generally moving a limb through $90^{\circ}$, or the head through $30^{\circ}-40^{\circ}$. Myoclonic jerks were seen in isolation or superimposed on tonic spasm of the same muscles. Movements of the arms were bilaterally synchronous or assynchronous. The muscle paroxysms occurred synchronously with guttural grunts and nasal exhalations in a nearly oneto-one relationship. Movements and vocalisations were highly regular, rhythmic, and stereotyped, and tended to be regularly repeating, in 2-5 minute bouts separated by a variable period from 1-20 minutes. Analysis of individual myoclonic jerks revealed an initial excursion of the head, neck or limb of $125-150 \mathrm{~ms}$ duration with considerable consistency. The muscle group may be held tonically in this new posture for a variable period of time to a maximum of 1-2 s, or rapidly returned to its initial position and tonically held, again for a variable period. The changing duration of the tonic postures gave the movements a somewhat varying frequency of $1-3 \mathrm{~Hz}$, though successive movements tended to be regular. A typical movement might involve sudden simultaneous opisthotonic arching of the back with the arms held in front bent at the elbow with rapid, regular, rhythmic and bilateral flexion and extension of the arms. A coarse $6-8 \mathrm{~Hz}$ tremor of the hands was noted with the arms in extension. The movements occurred at rest and with action. They interfered with movement and made some simple actions, such as wiping the nose, nearly impossible. There were no stimulus triggers.

Case 2 is a 10-year-old white girl. Family history of movement disorder, general medical history, perinatal history and maturational milestones are all non-contributory. The history of the movement disorder began at age 8 years with tonic squeezes of various muscle groups with superimposed myoclonic jerks. Over the course of the next six months and continuing to the time of examination the patient demonstrated tonic twisting and rotation of the outstretched hands with superimposed, regular, rapid, myoclonic movements. She had tonic movement of the torso to either side with superimposed rapid clonic jerks. Myriad vocalisations occurred, including repeated (4-5 times) hicupping, sneezing and barking noises, and unintelligible sounds such as "hihiahiahia" and woody woodpecker noises. Sounds were often associated and synchronised with head, arm, leg and torso myoclonic movements, tonic movements, or both myoclonic and tonic movements. She had vocalisations such as "dummy" and "shut-up," regularly repeated 4-5 times. There has been some waxing and waning, but no remission of symptoms. Although the movements are increased by stress and academic pressure, they occur quite spontaneously in neutral situations. The spasms may last up to half hour and then suddenly disappear. The movements cannot be voluntarily suppressed and interfere with ongoing voluntary activity. The patient had a brief trial of methylphenidate, $5 \mathrm{mg}$ qd, for attention deficit disorder and hyperactivity for several months prior to the onset of the movement disorder. Clonidine and haloperidol were ineffective and were discontinued. The general physical and neurological examinations were noncontributory. An awake EEG was reported as "borderline" due to excessive slowing in the theta range of unde- 
termined significance. A CT scan was negative. Prior psychological testing indicated the presence of mild attention deficit disorder, hyperactivity and learning disability. Although she does poorly in school and requires tutorial help, she is described as having no psychosocial difficulties. Videotape analysis. Analysis of the videotape of a several-hour interview revealed prominent vocal and motor symptoms. The vocalisations consisted of prolonged grunts lasting 1-2 seconds followed by clonic $2 \mathrm{~Hz}$ grunts. Five sneezes at one per second occurred in succession later followed by three hiccup sounds. In one typical sequence, a complex sequence of movements and vocalisations, which might be described as a single burst or flurry, lasted 4 seconds. In it, a sneeze was followed by a hiccup; a tonic, somewhat opisthotonic, arching of the back was followed by simultaneous symmetric tonic extension of both arms in pronation. Slower supination occurred in both hands, through $45^{\circ}$, followed by eight bilateral, rhythmic, superimposed myoclonic jerks of the hands, each jerk lasting about $200 \mathrm{~ms}$. The entire episode was accompanied by a loud tonic gutteral sound in synchrony with the movement pattern. Other common movements were isolated tonic arching of the back lasting 2 seconds, and tonic back arching with clonic jerks of both legs at 1 per second. Bursts of movement were separated by variable periods of seconds to minutes, generally 1 to 2 minutes. Movements could not be voluntarily inhibited and interfered with ongoing activity. They occurred with rest or action, and had a highly stereotyped form. There were no stimulus triggers.

Case 3 is a 17-year-old white male. Family history of movement disorder, family medical history, perinatal period, general medical history and developmental milestones are negative and non-contributory. At 3-4 years of age the patient developed repetitive tapping of the floor with pencils. Between ages 4-8 he developed a stereotypic "wo" sound lasting 1-2 seconds, and licking of objects between 6-9 years of age. These early symptoms were characteristic of stereotypic movement disorder. At age 15 he had the insidious onset of twisting tonic movements of the torso, arm and face, lasting several seconds, occurring 12 to 14 times a day. Within a period of months, the tonic movements were noted to have superimposed jerks of the face and head, and violent thrashing of his arms between his legs, in bursts lasting from minutes to hours. Repetitive grunting noises were associated with the movements. The symptoms have become more severe, requiring hospitalisation, and they now include the previously described movements in addition to severe repetitive myoclonic flexion of the entire upper trunk and head. The symptoms have had a marked waxing, waning and fluctuating clinical course. The movements are entirely non-suppressible and make normal activities impossible. There is no consistent change in the severity of symptoms with social stimuli except for slight decrease while concentrating on television, a movie, or reading. There were unsuccessful trials of haloperidol, clonidine, thiordazine, diazepam, clonazepam, carbamazepine, and reserpine. The general physical examination has been repeatedly negative. The neurological examination was negative except for some clumsy fine finger coordination and rapid alternating movements, and poor arm swing with walking. The patient has had normal EEGs, CT scan, lumbar CSF, blood screen and copper studies. The patient has had documented diagnoses of attention deficit disorder, hyperactivity, learning disability, and dyslexia since age 6 years. At age 7 the patient had a three-week trial of methylphenidate, dose unknown, which exacerbated the hyperactivity and movement disorder symptoms. Although the patient has performed poorly in school and is described as somewhat of a loner, there is no evidence of psychosis in major psychiatric disorder.

Case 4 a 9-year-old white male. Family medical and movement disorder histories and developmental milestones are non-contributory. He was delivered by $\overline{\overline{\vec{N}}}$ Caesarean section and has a history of allergies. The first $\overrightarrow{-}$ symptom of a movement disorder began at age $61 / 2$ with a nose twitch, followed in 3 months by wide stretching of the $\frac{\overline{\bar{O}}}{\bar{D}}$ mouth, and head nodding. Symptoms disappeared for 4 months followed by return of an up and down head shake, $\stackrel{\varnothing}{\Omega}$ a shoulder tic, and fast stamping. At age 9 he developed severe, regular, rhythmic, repetitive and thrashing clonic movements of the trunk, limbs and neck together with a $\vec{\circ}$ loud "ump" sound. These movements occur in paroxysms $\vec{\overrightarrow{ }}$ lasting for about 5 seconds and cannot be interrupted. A prodromal sensation is described as a hot sensation in the tip of the big toe which travels up to the head in about 30 seconds. Symptoms are the same inside and outside the home, decrease with non-anxious absorption in a task, and $\overrightarrow{0}$ do not vary in response to stress or anger. The symptom $\vec{i}$ have a waxing, waning, and fluctuating clinical course. The $\mathrm{N}$ patient has had an initially good response to haloperido $\$$ 윽 but severe symptoms were not adequately controlled ox $10 \mathrm{mg} /$ day. Psychotherapy has been ineffective. The stan $\vec{c}$ dard neurological examination was normal, as was the geri ฏ eral physical examination. Awake and sleep EEG and Cक्ठ scan were normal. Blood screening and copper studieg were normal. The patient has a history of hyperactivity and. $\vec{c}$ an attention deficit since age 6 , and is said to be a disciplint problem.

\section{Discussion}

Atypical characteristics displayed by these patients include (1) paroxysmal bursts of regular, repetitive, $\stackrel{\circ}{\mathcal{Q}}$ rhythmic, stereotypic, coordinated, simultaneous $\varrho$ and bilateral myoclonus and vocalisations often with $\overrightarrow{\overrightarrow{0}}$ tonic symptoms; (2) presence of hyperactivity and 3 attentional and learning disorders; (3) interference of symptoms with voluntary functioning; and (4) ineffectiveness of haloperidol.

A consideration of various disorders displaying myoclonus, dystonia, and tics can serve as back- $\overline{7}$ ground for a discussion of the differential diagnosis for these unusual cases.

Many different forms of primarily myoclonic disorders have been described since the description of $\frac{9}{7}$ "paramyoclonus multiplex" by Friedreich in $1881 .{ }^{5} \mathrm{D}$ Myoclonus, which occurs in numerous conditions, has been subject to multiple classifications, ${ }^{6}$ discussion of which is beyond the scope of this paper. Basic to all movements characterised as myoclonic, $\mathbb{O}$ 
however, is their brief, shock-like nature. The movements can be unilateral or bilateral, rhythmic or dysrhythmic, synchronous or asynchronous, elementary or complex. Many of the idiopathic forms are familial. ${ }^{7}$

The various manifestations of pure myoclonic disorders differ from the cases here described. First, and perhaps most importantly, vocalisations and words are not a manifestation of myoclonic disorders, regardless of type or aetiology. In a review of various aetiologies and types of myoclonus ${ }^{8}$ and in descriptions of essential familial myoclonus ${ }^{79}$ no vocalisations were reported. Another distinguishing characteristic of the movements of these four patients was the tendency of the myoclonic elements of the movements to be superimposed upon tonic posturing of involved body parts, or for the clonic phase of the movement of trunk or extremity to end in a tonic posture which was held for 1-2 seconds. This combination of myoclonus and dystonia is discussed in further detail later in this report. Moreover, the repetitive, bilateral, and synchronous nature of the movements in our patients is not characteristic of, or occurs rarely in, most forms of myoclonus. Finally, the absence of family history, seizures, associated neurological deficit, or known causes of myoclonic syndromes such as anoxia, system degeneration, infections, provides no basis for classification of this condition with other myoclonic disorders.

The occurrence of myoclonic features or tics in the dystonias or disorders classified as primarily dystonic in nature has been noted for over fifty years. Davidenkow ${ }^{4}$ described two siblings who at age 40 years developed a transient syndrome termed hereditary myoclonic dystonia, characterised by repetitive contractions of truncal musculature, particularly the neck, with simultaneous dystonic posturing in the same muscle groups. Movements were seen primarily with the patient at rest and, unlike the movements of our patients, abated with volitional movement. Other tics of the neck and facial muscles are described as well. ${ }^{10}$ Zeman et al ${ }^{11}$ suggest that tics, may occur in isolation as "formes frustes" in individuals within families with strong histories for idiopathic dystonia muscularum deformans. Benedek and Rakonitz ${ }^{12}$ describe a family with the combination of nose deformity and involuntary abnormal movements termed myoclonic torsion dystonia. The authors described the movements as myoclonic (varying combinations of isolated arrhythmic contractions of muscle groups that did not cause limb movement) and dystonic (prolonged neck and truncal movements causing rotating and bending of involved parts). Finally, Guggenheim and Dodge ${ }^{13}$ described two unusual cases, with the onset in childhood, of dystonic posturing of the arms with frequent, superimposed, flinging, semirhythmical jerks. One of the two cases responded to a combination of an anticholinergic with levodopa.

Other authors have noted the occurrence of myoclonic or tic-like phenomena in otherwise classical dystonia muscularum deformans. Thus, Wilson ${ }^{14}$ noted that the dystonic movements might be clonic or tic-like, and Fahn and Eldridge ${ }^{15}$ noted that dystonic movements may be "repetitive, jerky, or even tic-like." None of these descriptions, however, include vocal tics as part of the symptom complex. Shapiro and Shapiro ${ }^{16}$ indicated that $7 \%$ of their patients with Gilles de la Tourette syndrome have a combination of fast and slow symptoms.

Recently, Obeso et al ${ }^{17}$ described 14 patients with a combination of idiopathic torsion dystonia and myoclonic jerks, termed myoclonic dystonia. These patients, without a family history of movement disorder, were characterised as falling within the group of idiopathic torsion dystonia but having myoclonic jerks in addition to dystonic symptoms. The myoclonic symptoms tended to be of short duration (50$250 \mathrm{~ms}$ ), occasionally longer, irregular, and generally of large enough amplitude to interfere with activity. Frequently the same muscles were involved in the myoclonus and dystonia; however, myoclonus tended toward distal distribution while the dystonia was most evident proximally in the neck and shoulder muscles. Myoclonus and dystonia occurred at rest in most patients, and were stimulated by action in all patients. This resulted in the impression of myoclonus superimposed on the dystonia. In two patients, the myoclonic jerks were reported to occur regularly ("rhythmic myoclonus"). The movements were recorded by EMG in one of these patients and found to occur at a frequency of 3 to $4 \mathrm{~Hz}$ with each burst lasting about $100 \mathrm{~ms}$. There were no timelocked EEG events before the jerks. Age of onset in these patients ranged from 5 to 47 years, the symptoms generally developing over approximately five years with little subsequent progression. One patient had a prolonged remission. No abnormal vocalisations were reported.

Thus, the overlap between these movement syndromes is great. It becomes a matter of distinguishing the predominant movements and noting interrelationships between movements in the index case, then comparing them to prototype forms of each syndrome, and finally viewing them within the context of history and associated features. The cluster of rhythmic, coordinated, global, and bilaterally symmetric movements is not described in classic dystonia or myoclonus. In addition, most cases of dystonia are characterised by the prolonged sustained nature of the movements, and myoclonic features 
are minimal. The reverse is true for classical myoclonus. Myoclonic dystonia as described by Obeso et al, and other atypical cases, show features of both movements; however, again, rhythmic, coordinated and global features were generally not noted, and in particular in none of the aforementioned were vocalisations a major feature, as they are in the patients we describe (table).

Gilles de la Tourette syndrome is characterised by the onset of clonic tics and vocalisations during childhood and occasionally during adolescence. The motor and vocal tics are typically involuntary, fast, abrupt, ejaculatory and stereotypic clonic tics involving synergistic muscle groups. They usually occur irregularly as single discrete tics, occasionally in bursts of several tics, but are not rhythmically repetitive. The symptoms have a waxing, waning and fluctuating clinical course. Symptoms can be suppressed completely for short periods and partial inhibition of symptoms is always present. Occasional patients have tonic symptoms, lasting 1-3 seconds, which are voluntary in response to a disturbing sensory stimulus in the muscle part or a need to feel the muscle.' The dystonic symptoms, occurring in about $7 \%$ of patients, can be voluntarily inhibited more readily than the clonic tics. ${ }^{16}$ The symptoms and clinical course for Gilles de la Tourette syndrome are identical to chronic multiple motor tic except for the absence of vocal tics, and to transient tic of childhood except for complete remission within 1 (or 2) years. All of the tic symdromes usually respond to haloperidol and other neuroleptics. ${ }^{316}$

Paroxysmal myoclonic dystonia with vocalisation resembles Gilles de la Tourette syndrome because the age of onset is similar, and the symptoms include clonic and occasionally tonic movements and vocal- isations which are involuntary and stereotypic and have a waxing, waning and fluctuating clinical course. All four patients in this report had attentional, hyperactive and learning disorders which occur in 23 to 58 per cent of Gilles de la Tourette syndrome patients. ${ }^{316}$ However, unlike Gilles de la Tourette syndrome, the symptoms of paroxysmal myoclonic dystonia with vocalisations include prolonged bursts of regular, rhythmical and repetitive clonic movements and vocalisations often superimposed on tonic movements that cannot be inhibited, interfere with voluntary motor behaviour, and do not respond to haloperidol and other neuroleptics or chemotherapy. The relationship of attentional, hyperactivity, and learning disorders to the unique form of the abnormal movements suggests a common pattern of symptoms among these patients (table).

The small number of patients described here limits the generalisations that can be made when comparing this group with all other patients with unusual dyskinesias. However, at least two other patients in the atypical movement category had a similar history and pattern of signs, symptoms, and clinical course. Since videotapes were not made at initial evaluation and the patients were unavailable for reevaluation, reliable assessment was not possible and they were excluded from this report.

In summary, although individual clinical features demonstrated by these four patients are found singly in the other mentioned disorders, the clustering of these characteristics in the fashion described seems unique. This suggests a number of possibilities These patients may represent an atypical form of Gilles de la Tourette's syndrome or the simultaneous occurrence of that syndrome with myoclonus,

Table Comparison of five types of movement disorders*

\begin{tabular}{|c|c|c|c|c|c|}
\hline & Dystonias & Myoclonus & $\begin{array}{l}\text { Myoclonic } \\
\text { dystonia }\end{array}$ & $\begin{array}{l}\text { Gilles de la } \\
\text { Tourette } \\
\text { syndrome }\end{array}$ & $\begin{array}{l}\text { Paroxysmal } \\
\text { movement disorder } \\
\text { with vocalisations }\end{array}$ \\
\hline $\begin{array}{l}\text { Tonic contractions } \\
\text { Abrupt contractions } \\
\text { Rhythmic } \\
\text { Bilaterally symmetric } \\
\text { Stereotyped } \\
\text { Paroxysmal } \\
\text { Interference with }\end{array}$ & $\begin{array}{l}++++ \\
+1++ \\
+ \\
+ \\
+1++ \\
+1++\end{array}$ & $\begin{array}{l}+1++ \\
++++ \\
+ \\
+ \\
+1++ \\
++\end{array}$ & $\begin{array}{l}+++ \\
+++ \\
++ \\
+ \\
++ \\
\text { variable }\end{array}$ & $\begin{array}{l}++ \\
++++ \\
+ \\
+ \\
++++ \\
+\end{array}$ & $\begin{array}{l}++++ \\
++++ \\
++++ \\
++++ \\
++++ \\
++++\end{array}$ \\
\hline $\begin{array}{l}\text { voluntary movement } \\
\text { Vocalisations } \\
\text { Family history }\end{array}$ & $\begin{array}{l}+++ \\
+ \\
\text { may be familial }\end{array}$ & $\begin{array}{l}++++ \\
+ \\
\text { may be familial }\end{array}$ & $\begin{array}{l}++ \\
+ \\
\text { non-familial }\end{array}$ & $\begin{array}{l}+ \\
++++ \\
8 \% \text { with Gilles de } \\
\text { la Tourette } \\
\text { syndrome } 42 \% \\
\text { with other tic } \\
\text { disorders }\end{array}$ & $\begin{array}{l}++++ \\
++++ \\
\text { non-familial }\end{array}$ \\
\hline Treatment response & variable & variable & variable & $\begin{array}{l}\text { Good response } \\
\text { to haloperidol }\end{array}$ & $\begin{array}{l}\text { Poor response } \\
\text { to haloperidol }\end{array}$ \\
\hline
\end{tabular}

$*+++$ : always present or clincally prominent.

+++ : usually present or of moderate clinical importance.

++ : occasionally present or plays minor clinical role.

+ : rarely present or clinically insignificant. 
dystonia or even myoclonic dystonia. On the other hand, the possibility should not be overlooked that these cases might represent an as yet unrecognised entity with a specific pathophysiology. We propose paroxysmal myoclonic dystonia with vocalisations be considered as a possible diagnostic entity which may help clarify the problem of heterogeneity in tic conditions. ${ }^{1819}$

We acknowledge support of this study from the Tourette, Tic \& Movement Disorders Foundation, H \& F Sarkowsky, Gateposts Foundation, Shimberg Foundation, H Stein, and other grantors.

\section{References}

' Shapiro E, Shapiro AK. Seminology, nosology and criteria for tic disorders. Rev Neurol (Paris) (in press).

${ }^{2}$ American Psychiatric Association Task Force on Nomenclature and Statistics. Diagnostic and Statistical Manual of Mental Disorders, ed 3. Washington: American Psychiatric Association, 1980.

${ }^{3}$ Shapiro AK, Shapiro E, Bruun RD, Sweet RD. Gilles de la Tourette Syndrome. New York: Raven Press, 1978.

${ }^{4}$ Davidenkow S. Auf hereditar-abiotrophischer Grundlage Akut auftretende, regressierende und episodische Erkrankungen des Nervensystems und Bemerkungen über die famillare subakute, myoklonische. Dystonie $Z$ ges Neurol Psychiat 1926;104:596-622.

${ }^{5}$ Friedrich N. Neuropathologische Beobachtungen beim Paramyoclonus multiplex. Virchows Arch [Pathol Anat] 1981;86:421-3.

${ }^{6}$ Marsden CD, Obeso JA, Rothwell JC. Clinical neurophysiology of muscle jerks: Myoclonus, chorea, and tics. In: Desmedt JE, ed. Motor Control Mechanisms in Health and Disease. New York: Raven Press, 1983.
${ }^{7}$ Przuntek H, Muhr H. Essential familial myoclonus. $J$ Neurol 1983;230: 153-62.

${ }^{8}$ Swanson PD, Lutterell CN, Magladery JW. Myoclonus-A report of 67 cases and review of the literature. Medicine 1962;41:339-56.

${ }^{9}$ Daube JR, Peters HA. Hereditary essential myoclonus. Arch Neurol 1966;15:587-94.

${ }^{10}$ Zeman W, Whitlock CC. Symptomatic dystonias. In: Vinken PJ, Bruyn GW, eds. Handbook of Clinical Neurology, Vol 6. Amsterdam: North Holland 1968:544-66.

"Zeman W, et al. Idiopathic dystonia muscularum deformans. II. The formes frustes. Neurology (Minneap) 1960; 10: 1068-75.

${ }^{12}$ Benedek L, Rakonitz E. Heredopathic combination of a congenital deformity of the nose and of myoclonic torsion dystonia. J Nerv Ment Dis 1940;91:608-16.

${ }^{13}$ Guggenheim MA, Dodge PR. Unusual arm movements with onset in childhood-a nosologic entity. Trans Am Neurol Assoc 1970;95:182-6.

${ }^{14}$ Wilson SAK. In: Bruce AN, ed. Neurology Vol 2. London: Edward Arnold, 1940:832-7.

is Fahn S, Eldridge R. Definition of dystonia and classification of the dystonic states. Adv Neurol 1976; 14: 1-5.

${ }^{16}$ Shapiro AK, Shapiro E. Tourette syndrome: Clinical aspects, treatment and etiology. Seminars in Neurology, Movement Disorders 1982;2(4):373-85.

${ }^{17}$ Obeso JA, Rothwell JC, Lang AE, Marsden CD. Myoclonic dystonia. Neurology (NY) 1983;33:825-30.

${ }^{18}$ Caine ED, Polinsky RJ, Ludlow CL, Ebert MH, Nee LE. Heterogeneity and variability in Tourette syndrome. In: Friedhoff AJ, Chase TN, eds. Advances in Neurology, Vol 35, Gilles de la Tourette Syndrome. New York: Raven Press, 1982:437-42.

${ }^{19}$ Shapiro AK, Shapiro E. Tourette syndrome: history and present status. In: Friedhoff AJ, Chase TN, eds. Advances in Neurology, Vol 35, Gilles de la Tourette Syndrome. New York: Raven Press, 1982:17-23. 